MATEC Web of Conferences 44, 02022 (2016)

DOI: $10.1051 /$ matecconf/20164402022

(C) Owned by the authors, published by EDP Sciences, 2016

\title{
Research on Multi Position and Parallel Detection Device for Universal Circuit Breaker Controller
}

\author{
Xiang Fei Meng ${ }^{1 a}$, Qi Xie ${ }^{1}$, Hui Gang Xu ${ }^{1}$ \\ ${ }^{1}$ Changshu Institute of Technology, School of Electrical and Automation Engineering, Changshu 215500, China
}

\begin{abstract}
This paper introduces a design scheme of the residual current electrical fire monitoring detector performance test system based on virtual instrument technology. In order to test different current specifications monitor detector compatiblly, the system combines virtual instrument technology and computer control technology to improve the accuracy of output current of the current generator with electric voltage compensation technology and the way of closed-loop control, and designs two sets of different size and the same type of pneumatic fixture to solve the connection of different specifications monitoring detector, software design adopts layered structure and the method based on configuration files, to better satisfy all kinds of test requirements for different products. Practical application shows that the system has the testing results of accurate, high efficiency and convenient operation.
\end{abstract}

\section{Introduction}

Universal circuit breaker is a kind of switch device which is used to protect and control various kinds of faults such as the power system. the power system and the equipment overload, under voltage, short circuit and ground fault. Its core is its internal controller unit, the Universal circuit breaker protection control is achieved through its internal core unit - controller.

The multi station parallel test system described in this paper is a system designed to test the controller before assembling the circuit breaker. Can improve the efficiency of testing equipment, reduce the testing cost of the whole system, and solve the problem of rapid product testing in mass production.

\section{System function analysis}

Universal circuit breaker controller mainly includes control and execution. The function of control part is to measure the input signal size and according to the signal size, according to the requirements of the action to protect the performance of the signal, and to promote the implementation of the action. so as to achieve a variety of circuit breakers. As a result, the Universal circuit breaker controller testing system should have the following test function.

(1) Measurement function test. The universal circuit breaker controller can measure the electric parameters such as current, voltage, power, frequency, power and so on. It has high measurement accuracy, and its multi character protection function is based on the measurement function. So the testing function of circuit breaker is the foundation of the whole test. The test

\footnotetext{
a Xiangfei Meng: mxf0316@163.com
}

system can test the function of the controller in accordance with the error type and size according to the product specification.

(2) Multi feature protection function test. It Can carry out the three section of circuit breaker protection, grounding protection, reverse power protection, protection, over frequency, under voltage protection, over voltage protection, current imbalance protection, ZSI protection and other protection functions of the test. The test system can control the signal source to output a given signal according to the different specifications and different testing items of the controller, and test whether the protection function is correct and the action time is within the specified error range. The key to the testing of the multi characteristics protection function is to provide accurate, high accuracy and high voltage test signal.

(3) Communication function test. The "four remote" function of the circuit breaker can be realized by using the Modbus-RTU mode on the RS485 interface.

\section{Comparison of test plan}

There is only one station in the traditional test bench, and it is tested by the equipment and instruments, and the single test equipment is used to test the product. The resource utilization is low and the production efficiency is not ideal. For the testing of large quantities of products, the use of multi station testing method is more and more people's recognition and gets more promotion. But there are some limitations to increase the number of stations, must be in the appropriate number of cases to take other techniques to further improve efficiency.

In multi station testing, there are many kinds of technologies, such as serial test, pipeline test, parallel test. 
In this system, we use the parallel test and it can complete the same test tasks at the same time of five stations. Such arrangement is advantageous to reduce the difficulty and complexity of the software design. Through the use of multi station parallel testing technology can significantly improve the throughput of the test system, and further improve the utilization of resources and production efficiency.

Take five test system as an example, if the test Project is 3 , the serial test (Table 1), the assembly line test (Table 2 ), and the parallel test (Table 3 ) are described in table three. Through observation, it is easy to draw the conclusion that in the multi station test, the test time is the longest, and the time of parallel test is the shortest, the efficiency of parallel test is the highest.

Table 1. Serial test

\begin{tabular}{|c|c|c|c|c|c|}
\hline $\begin{array}{c}\text { time } \\
\text { slice }\end{array}$ & $\begin{array}{c}\text { Station } \\
1\end{array}$ & $\begin{array}{c}\text { Station } \\
2\end{array}$ & $\begin{array}{c}\text { Station } \\
3\end{array}$ & $\begin{array}{c}\text { Station } \\
4\end{array}$ & $\begin{array}{c}\text { Station } \\
5\end{array}$ \\
\hline 1 & Project 1 & & & & \\
\hline 2 & Project 2 & & & & \\
\hline 3 & Project 3 & & & & \\
\hline 4 & & Project 1 & & & \\
\hline 5 & & Project 2 & & & \\
\hline 6 & & Project 3 & & & \\
\hline 7 & & & Project 1 & & \\
\hline 8 & & & Project 2 & & \\
\hline 9 & & & Project 3 & & \\
\hline 10 & & & & Project 1 & \\
\hline 11 & & & & Project 2 & \\
\hline 12 & & & & Project 3 & \\
\hline 13 & & & & & Project 1 \\
\hline 14 & & & & & Project 2 \\
\hline 15 & & & & & Project 3 \\
\hline
\end{tabular}

Table 2. Pipeline testing

\begin{tabular}{|c|c|c|c|c|c|}
\hline $\begin{array}{c}\text { time } \\
\text { slice }\end{array}$ & $\begin{array}{c}\text { Station } \\
1\end{array}$ & $\begin{array}{c}\text { Station } \\
2\end{array}$ & $\begin{array}{c}\text { Station } \\
3\end{array}$ & $\begin{array}{c}\text { Station } \\
4\end{array}$ & $\begin{array}{c}\text { Station } \\
5\end{array}$ \\
\hline 1 & Project 1 & & & & \\
\hline 2 & Project 2 & Project 1 & & & \\
\hline 3 & Project 3 & Project 2 & Project 1 & & \\
\hline 4 & & Project 3 & Project 2 & Project 1 & \\
\hline 5 & & & Project 3 & Project 2 & Project 1 \\
\hline 6 & & & & Project 3 & Project 2 \\
\hline 7 & & & & & Project 3 \\
\hline
\end{tabular}

Table 3. Parallel test

\begin{tabular}{|c|c|c|c|c|c|}
\hline $\begin{array}{c}\text { time } \\
\text { slice }\end{array}$ & $\begin{array}{c}\text { Station } \\
1\end{array}$ & $\begin{array}{c}\text { Station } \\
2\end{array}$ & $\begin{array}{c}\text { Station } \\
3\end{array}$ & $\begin{array}{c}\text { Station } \\
4\end{array}$ & $\begin{array}{c}\text { Station } \\
5\end{array}$ \\
\hline 1 & Project 1 & Project 1 & Project 1 & Project 1 & Project 1 \\
\hline 2 & Project 2 & Project 2 & Project 2 & Project 2 & Project 2 \\
\hline 3 & Project 3 & Project 3 & Project 3 & Project 3 & Project 3 \\
\hline
\end{tabular}

But from the point of view of resources, not all tasks can be tested in parallel, such as the use of the same test resource tasks can only be serial test. So it is necessary to solve the problem of resource allocation in the multi station test system.

\section{Test task decomposition and resource allocation}

Test task decomposition is the precondition and foundation of the parallel test, which affects the execution efficiency and execution time of the parallel test. It Should be based on task decomposition and normalization, the strong correlation of relative independence as the basic principle, and considering the resource usage and production enterprises of task decomposition, the decomposition of coarse and fine testing are not conducive to the project management and scheduling.

\section{Test system design}

The overall structure diagram of Universal control unit inspection device is shown in Figure 1. The main industrial control computer, NI data acquisition card based on PCI bus, three phase standard signal source, single station test interface circuit, current, voltage monitoring module, communication module and test stand, etc.. Circuit breaker controller can be conveniently placed in the test station of the station, through a variety of terminal connection. Power parameter measurement module WB1831B35 is used to measure the electric parameters of the three phase standard signal source.

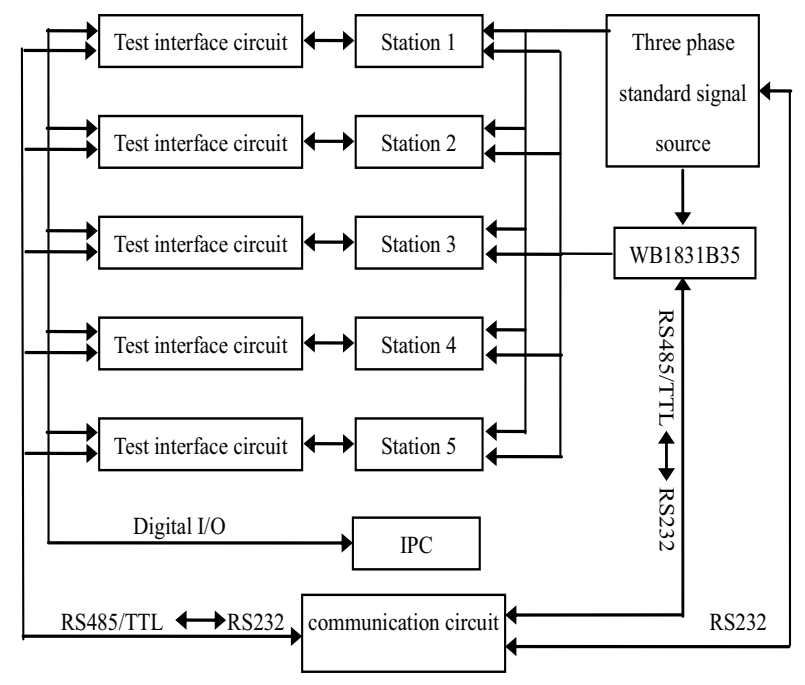

Figure 1. The test system block diagram

\subsection{Three phase current and voltage signal generating circuit}

The three-phase current signal generator used to produce various specifications of Universal and Universal series control components of the current test signal, the threephase current signal generator can generate three-phase $0 \sim 4.2 \mathrm{~V}$ voltage to current signal simulation 0 82000A. through computer control can realize phase modulation, frequency modulation and amplitude modulation function.

Three phase voltage signal generating circuit for generating voltage test signals of various specifications of UNIVERSAL and Universal series control components. The voltage generator can generate $0 \sim 1000 \mathrm{~V}$ three-phase voltage (line voltage). the computer control can realize phase modulation, frequency modulation and amplitude modulation function. Three phase current and voltage signal generation principle is shown in figure 2 . 


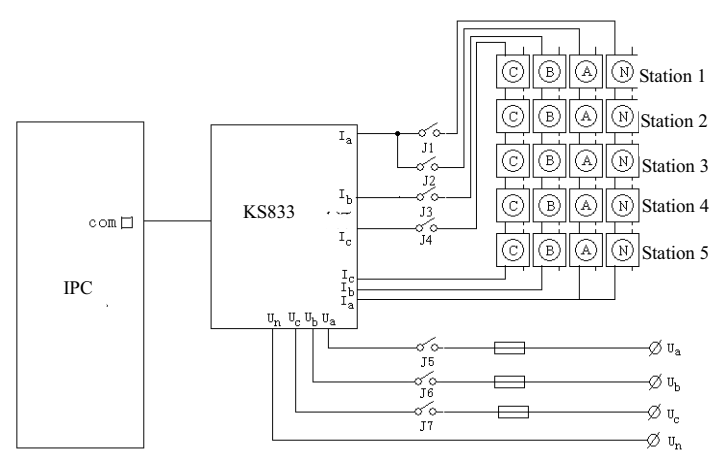

Figure 2. Three phase current and voltage signal generation principle

\subsection{System software design}

LabVIEW is one of the most widely used virtual instrument software to development platform, which is used in the field of instrument control, data acquisition, data analysis and data display. It is a powerful and convenient integrated development environment. Test system software is designed and developed in the LabVIEW environment. it can better reflect the hierarchical and modular, and enhance the maintainability and scalability of the system software. The key to execute the parallel test system of multi station parallel test system is to write the test program, and the design of the test software should be considered together with the hardware design of the system.

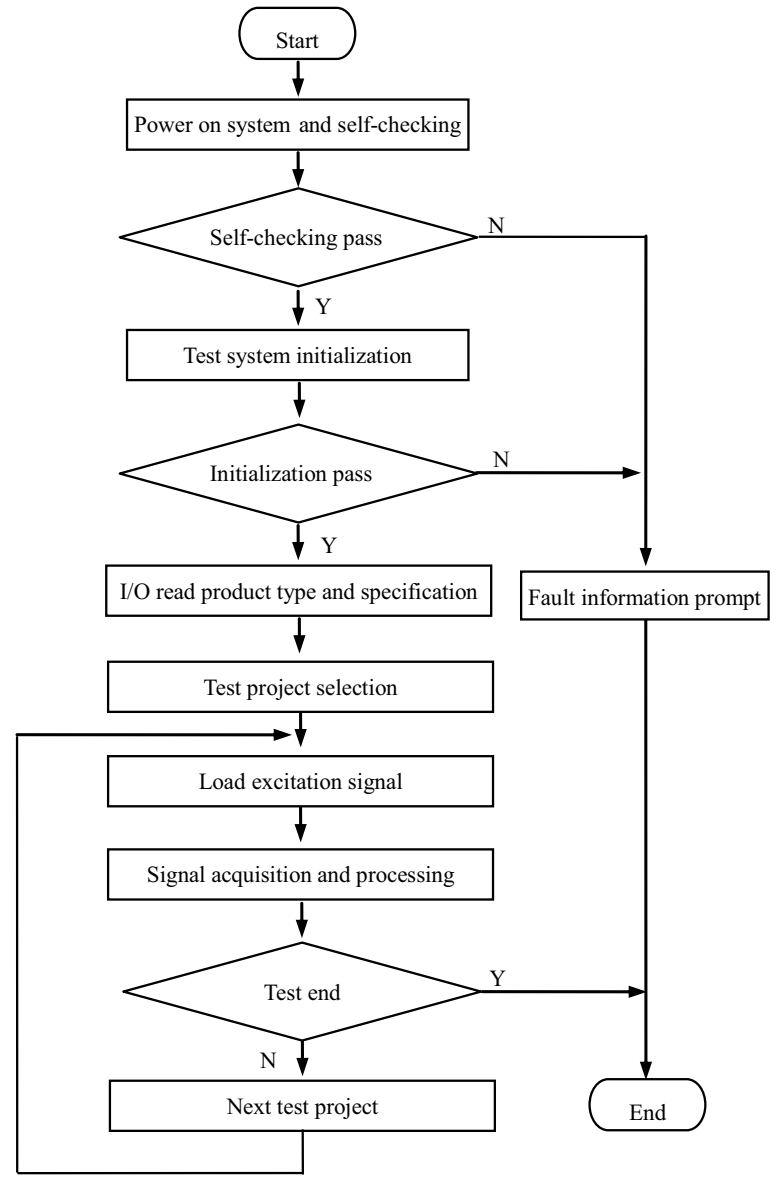

Figure 3. Test system software work flow chart
Universal circuit breaker controller testing system software adopts hierarchical structure and modular design ideas, for easy management and scheduling, each test project as a separate module, all test items can be selected according to the actual situation to do or not do, and stored in the system configuration file, so that the use of the test system becomes more flexible and convenient. System software mainly includes testing the main program, the system initialization program, the program control voltage source control program, the program controlled current source control program, the test program module, the report generation program, etc.. Test system main program for the whole system scheduling, coordination role. System work flow chart is shown in figure 3.

\section{Conclusion}

This paper introduces the automatic test system of Universal circuit breaker controller which combines the virtual instrument technology and computer control technology. Through the design of the array type threephase current source and the three-phase voltage source, it can realize multi position test and parallel test. Compared with the traditional automatic test system, the test system has the advantages of high efficiency, high resource utilization and high efficiency. Practice shows that this method has high practical value and good prospect of promotion, it is a practical and feasible solution.

\section{Acknowledgements}

This paper is supported by the Jiangsu Province research joint innovation fund project (NO. BY2014075)

\section{References}

1. Feng Guanshui. Reasonable selection and application of intelligent CW3 series circuit breaker [J]. Jiangsu electric, 2008, (3):34-36.

2. Xu Ming, Hu Leigang, Zhou Yuewin. Parallel test task parallelism analysis $[\mathrm{J}]$. computer engineering, 2009.35 (4): 56-60.

3. Hao Hongwu, Zhang Jun. Multilateral Detecting Optimum Design in Industrial Automatic Production. [J]. Journal of $\mathrm{Xi}^{\prime}$ an Aerotechnical College, 2004, 22(5):32-34. 